\title{
The role of cultural familiarity on customer satisfaction in the context of hotel service failure
}

\author{
Trianasari, B.Sparks, \& K.Butcher \\ Griffith University, Gold Coast
}

\begin{abstract}
This paper reports the findings of a study that investigates the effects of severity of service failure and cultural familiarity on customer satisfaction. The study also examines the interaction effect between these two independent variables. An exploratory study using six focus groups was undertaken to elicit insights into the potential influences of the proposed variables on customer satisfaction. The findings from the focus groups were used to develop the stimulus material for an experimental research design. Ultimately, a 3 (cultural familiarity: low, medium, high) x 3 (severity of failure: low, medium, high) experimental design was employed. Using an online survey method, 740 respondents were randomly assigned to various scenario conditions and were asked to rate their satisfaction levels (measured using a multi-item scale). Significant results were found from the analysis of the data using ANOVA. Theoretical and practical contributions of the study, limitation and suggestions for future studies are discussed.
\end{abstract}

Key words: Satisfaction, cultural familiarity, severity of failure, service failure, service encounter.

\section{INTRODUCTION}

Being the ultimate goal of any service firm, customer satisfaction has long been a central topic in the marketing field, whereby large amounts of research has been conducted. However, despite the huge body of literature on this topic, scholars continue to be attracted to conduct research on customer satisfaction for both theoretical advancement purposes and practical implications (e.g., Bowen \& Chen, 2001; Furrer, Liu, \& Sudharsan, 2000; Sabharwal, Soch, \& Kaur, 2010; Wu, 2011). In the tourism and hospitality sector, this topic has often been linked to the cultural background of the customer and the service provider (e.g., Reisinger \& Turner, 2001; Smith, Bolton, \& Wagner, 1999; Weiermar, 2000). Indeed, incorporating cultural aspects into tourism customer satisfaction studies are deemed important due to the increasing global opportunities for international travel and interaction. Therefore, people from different cultures engage in service interactions. Furthermore, the cultural interaction between customers and service providers during service encounters might lead to different interpretations, perceptions and evaluations toward the service performance in the minds of both the customers and the service provider (Strauss \& Mang, 1999). Consequently, service per- formance variations might be regarded by certain customers as a failure due to cultural differences.

The link between cultural differences and customer satisfaction in the context of service failure has also been extensively studied (eg., Patterson \& Mattila, 2008; Patterson, Cowley, Prasongsukarn, 2006). However, the majority of these studies have focused on the national cultural background that an individual (either the customer or the service provider) possesses. Whilst it is critical to understand cultural differences/similarities between customers and service providers in the tourism field (Weaver \& Lawton, 2010), customers' familiarity with the culture of the destination might also play an important role toward satisfaction. For example, familiarity with the way the service is delivered in various countries may have an impact on how a customer evaluates the service standards. This is particularly true when service failures occur, whereby customers may weight the same failure differently depending on their familiarity toward the culture of the destination.

Thus, understanding customers' evaluation toward service performance from the perspective of cultural familiarity is also considered essential. However, there are limited studies which have addressed this issue. Therefore, this study extends the limited lit- 
erature by investigating the role of cultural familiarity on customer satisfaction by incorporating different levels of service failure severity. The study also examined the interaction effect between the two independent variables of cultural familiarity and severity of service failure.

Following this introduction, the paper presents the literature review, research methods, results, discussion and finally the conclusion.

\section{LITERATURE REVIEW}

This section provides a brief overview of the literature supporting this study: customer satisfaction, service failure, and cultural familiarity respectively.

\subsection{Customer satisfaction}

Customer satisfaction has occupied a central position in the service and marketing literature. Customers evaluate service performance before, during and after service consumption. Based on their evaluations, customers develop feelings of satisfaction or dissatisfaction (Bitner, Brooms, \& Mohr, 1994). More specifically, satisfaction or dissatisfaction results from the comparison of customers' prior expectations and the actual service performance (Oliver, 1980). When a service performance does not meet the customer's expectations, the customer will be dissatisfied. On the other hand, when a service performance meets the customer's expectations, the service is considered satisfactory.

Customer satisfaction is thus used to measure the level of the service performance. This evaluation is seen from the eyes of the customer, and even though service providers have performed to their best, the outcome may still be regarded as dissatisfying by customers. Thus, customers are the true judges of service quality however, their judgments are relatively subjective. This subjectivity might arise from the different experiences that each customer possesses. Accordingly, the subjectivity of customers' evaluations might also result from the level of their familiarity with the culture of the destination. That is, their previous experiences or current knowledge of this destination context. However, despite being heavily researched within the context of the hospitality sector, where cultural interactions between customers and service providers from different backgrounds often occur, customer satisfaction has rarely been integrated with cultural familiarity. For this reason, this study enhances the understanding of customer (dis)satisfaction toward service failure by incorporating cultural familiarity. Before discussing cultural familiarity in depth, a brief review of what constitutes a service failure is presented.

\subsection{Service failure}

Being performed by humans instead of machines, service encounters may not be $100 \%$ standardized and error free. Thus, during any service encounter, service failure is a common phenomenon and is to some extent unavoidable, even in well organized and well established service firms (Mattila, 2001). Service failure is defined as a mistake or error while services are being delivered to customer(s) (Lewis \& Spyrakopoulos, 2001). This error might be caused by the manner of the staff (interpersonal failure) or the system (functional failure) (Smith et al., 1999) and, might trigger customer dissatisfaction (Sparks \& McColl-Kennedy, 2001).

As we might logically expect, research in the area of service failure has found that customer dissatisfaction toward service failure might depend upon the magnitude of the failure (Smith et al, 1999). While this statement is fairly obvious at first glance, we suggest that different levels of failure severity might elicit different levels of responses and more importantly interact with cultural familiarity as a precursor to customer satisfaction (see hypothesis 3). As such, the following hypothesis was proposed:

\section{Hypothesis 1}

There are differences in the levels of customer's satisfaction based on the level of the severity of service failure.

\subsection{Cultural familiarity}

Culture is identified as a broad, complex, unique, multidimensional, and abstract concept (Donthu \& Yoo, 1998; Patterson \& Mattila, 2008; Reisinger \& Turner, 2001) that is manifested in many aspects of human life. Amongst other things, culture forms people's behaviour, habits, attitudes, and beliefs. In the service oriented marketing literature, culture has been often been linked to customer satisfaction. However, the attention has mainly focused on the cultural differences between customers and service providers (Reisinger \& Turner, 1997; Patterson \& Mattila, 2008). In contrast, the present research focuses on familiarity, which refers to the levels of awareness or knowledge about an object such as a product, either service or good. This product or service awareness might be obtained from information search, previous experience, or a third party's recommendation, such as friends, relatives, or travel agencies. Thus, cultural familiarity in this study refers to the awareness of culture, language, food, communication, and service standards of the destination.

Much research has reported the role of product familiarity on customer evaluation (e.g., Rao \& Monroe, 1988). That is, the more familiar a customer is with the product/focal service provider, the 
higher the customer's evaluation will be (eg., Patterson \& Mattila, 2008) . However, customers might become more demanding when they are familiar with the product. Thus, the opposite result might be obtained, whereby the more familiar customers are toward a product, the lower their evaluation will be. Similarly, in the context of familiarity with the culture of a destination, the more familiar are customers; the lower their evaluation will be. However, while there have been a number of studies that link the concept of product familiarity to customer satisfaction, little has been done using the aspect of familiarity with the culture of a destination. Therefore, this study answered whether or not cultural familiarity is able to explain the variations in customer satisfaction levels. Thus, the following hypothesis was proposed:

\section{Hypothesis 2}

Customer's satisfaction differs based on the level of cultural familiarity.

Whilst the severity of failure and cultural familiarity have been proposed to influence customer satisfaction, it is essential to understand whether customer satisfaction toward high failure severity is the same whether or not the customer is familiar or unfamiliar with the culture of the location of the service failure. Thus, it is arguable that there is an interaction effect between these two independent variables. Therefore, in addition to the previous hypotheses, the following hypothesis was proposed:

\section{Hypothesis 3}

An interaction effect exists between the severity of failure and cultural familiarity leading to customer satisfaction.

\section{RESEARCH METHODS}

This study employed a sequential mixed-methods approach. First, an exploratory study using focus groups was undertaken to elicit insights into the potential influences of the proposed variables on customer satisfaction (Trianasari, Sparks, \& Butcher, 2011). Twenty nine Australians were recruited in six separate group discussions. The findings from the focus group were used to develop the stimulus material for the present study. A 3 (cultural familiarity: low/Russia, medium/Indonesia, high/Australia) $\times 3$ (severity of failure: low, medium, high) experimental design was employed. Data were collected from 740 Australians via an online based survey method. The respondents were randomly assigned to various scenario conditions and were asked to rate their level of satisfaction (measured using a multiitem scale). Prior to the main data analysis, realism and manipulation checks were performed in order to ensure that the manipulations worked as intended (Perdue \& Summer, 1986). Next, a series of ANOVA were conducted to test the hypotheses.

\section{RESULTS}

This section presents the results of the two preliminary tests of the credibility and manipulation effectiveness of the stimulus material and the hypotheses testing.

\subsection{Credibility and manipulation checks}

A number of measures were included to test the credibility of the treatments and the manipulations of the independent variables. The results of these tests which used a 7-point scale were satisfactory. For the credibility checks, four items were used to represent realism of the scenario (eg., 1= very unrealistic, $7=$ very realistic) and the ease of the participants to imagine the scenario (eg., $1=$ very easy, 7 = very difficult). The respondents found the service conditions were realistic and were able to play the role as a hotel guest (the lowest $M=5.5$ ). For the manipulation tests, it can be explained briefly that the respondents viewed the description of severity of failure and cultural familiarity to be different in the predicted directions. Hence, the manipulations of the factors in each of the independent variable were deemed valid $\left(M_{\text {low }}=3.40, \mathrm{SD}=1.56 ; M_{\text {medium }}=4.13, \mathrm{SD}=1.41\right.$; $M_{\text {high }}=4.48, \mathrm{SD}=1.41$ for severity of failure and $M_{\text {low }}=2.55, \mathrm{SD}=1.30 ; M_{\text {medium }}=3.61, \mathrm{SD}=1.43$; $M_{\text {high }}=6.34, \mathrm{SD}=.81$ for cultural familiarity). The next step was to test the hypotheses which are discussed in the next sub-section.

\subsection{Hypotheses testing}

The results show significant main effects for severity of failure and cultural familiarity on customer satisfaction $F(2,730)=15.44, p=.000, \mathrm{y}^{2}=.04$ and $F$ $(2,730)=3.49, p<.05, \mathrm{y}^{2}=.01$ respectively. These findings suggest statistical support for hypotheses 1 and 2 . The respondents reported different levels of satisfaction in different conditions of severity of failure and cultural familiarity. Further analysis was conducted to understand which groups differ by performing a post hoc test using Tukey's technique. This test revealed that dissatisfaction was greater for those in the medium/high failure severity conditions compared to the low severity conditions. Furthermore, a similar test was performed to understand which of the cultural familiarity groups differed. However, no difference in the dissatisfaction levels of low, medium and high familiarity was found. 
More importantly, these main effects were quailfied by an interaction effect between cultural familiarity and severity of failure, $F(4,730)=3.24$, $\mathrm{p}<.05, \mathrm{y}^{2}=.02$, which suggests that hypothesis 3 is supported. The mean scores of the simple effect of failure severity within cultural familiarity on satisfaction are shown in Table 1 . The univariate $F$ tests of the simple effect of the severity of failure within each level of cultural familiarity were found significant $\left(F_{\text {low }}(2,730)=6.55, \mathrm{p}<.01 ; F_{\text {medium }}(2,730)=\right.$ $\left.4.20, \mathrm{p}<.05 ; F_{\text {high }}(2,730)=10.30, \mathrm{p}<.05\right)$. However, the simple effect of cultural familiarity within each level of severity of failure was only significant for high level of severity $(F(2,730)=5.63, \mathrm{p}<.01)$. Furthermore, the simple effects analyses show that the main source of the interaction effect occurs in the highest level of cultural familiarity. That is, the level of dissatisfaction is substantially greater when cultural familiarity is high for the high severity of failure condition, suggesting greater levels of satisfaction when the customer is unfamiliar with the culture. In other words, within the high familiarity condition, respondents displayed lower satisfaction when the severity of failure was high versus low or medium; whereas within the medium or low familiarity condition, respondents expressed a lower level of satisfaction for medium or high severity of failure compared to low severity. Whereas, within the low level of severity, respondents showed lower satisfaction for the medium/high familiarity compared to the low level of familiarity. This interaction effect is demonstrated in Figure 1.

Table 1. Mean scores of failure severity and cultural familiarity on satisfaction

\begin{tabular}{|c|c|c|c|c|}
\hline & \multicolumn{3}{|c|}{ Cultural familiarity } & \multirow{2}{*}{$\begin{array}{l}\text { Severity of failure } \\
\text { Average }\end{array}$} \\
\hline & Low & Med & High & \\
\hline \multicolumn{5}{|l|}{$\begin{array}{l}\text { Severity } \\
\text { of failure }\end{array}$} \\
\hline Low & 3.12 & 2.89 & 2.69 & 2.90 \\
\hline Medium & 2.54 & 2.32 & 2.66 & 2.51 \\
\hline High & 2.46 & 2.45 & 1.86 & 2.66 \\
\hline \multicolumn{5}{|l|}{$\begin{array}{l}\text { Cultural } \\
\text { familiarity }\end{array}$} \\
\hline Average & 2.71 & 2.55 & 2.40 & \\
\hline
\end{tabular}

\section{DISCUSSION}

The finding of this study confirmed the results of the existing literature that failure severity is an important determinant of customer satisfaction (eg., Smith et al., 1999). That is, the more severe the service problem, the less satisfied the customer will be. This study also supported its key hypothesis that cultural familiarity affects customer satisfaction significantly. That is, differences in customer satisfaction

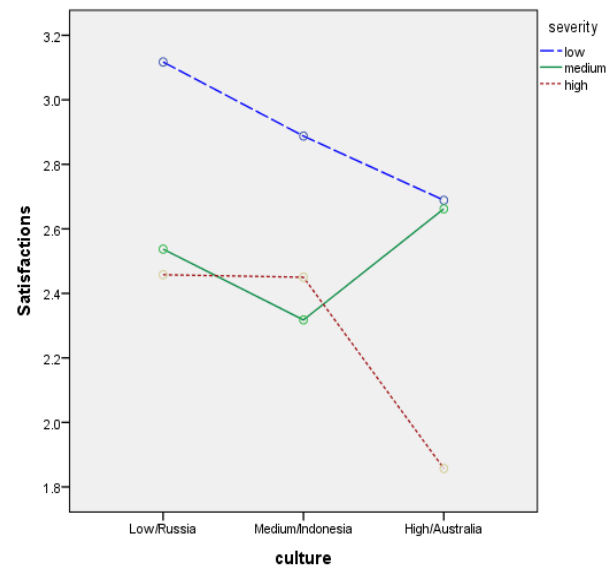

Figure 1 . The effects of severity of failure and cultural familiarity on customer satisfaction.

can be explained by different levels of cultural familiarity. With different levels of cultural familiarity, people might have different criteria for service quality and thus, respond differently when failure occurs. Moreover, from the effect sizes, it can be noted that compared to cultural familiarity, the severity of failure is more important to explain the variations in the customers' levels of dissatisfaction.

In addition to the finding of the main effects, the unique interaction effect of the severity of failure and cultural familiarity was also found. That is, the variation in the levels of satisfaction is not simply the effect of severity of failure but is also impacted by how familiar a person is with the culture. In particular, for high severity failures, when a person is also very familiar with the culture the same event is seen to be much more dissatisfying compared to when it occurs in a less familiar environment. This finding offers the key contribution to the literature.

\subsection{Practical Contributions}

For business practices, whilst it is hard to perform a $100 \%$ failure free service performance at all times, it is important to consistently make a considerable effort to minimize service failures in terms of number and severity. Keeping failures at minimum levels could be achieved through continued training programs, particularly for employees who have direct contact with hotel guests. Moreover, attention should be paid to the cultural interaction skills and the knowledge of customers' levels of cultural familiarity with the destination. This program would help employees to anticipate customers' responses when failures occur. However, this does not imply that customers who have a low level of cultural familiarity and who tend to have higher satisfaction should be neglected and the service failures should be left unsolved. Employees should treat customers equally and at the same time should be able to anticipate and respond when customers, who have either a low or high cultural familiarity, experience service failure. 
In addition, segmentation can also be made in term of levels of cultural familiarity, thus, service performance can be tailor-made, based on this segmentation. With this strategy, service failure can be minimized.

\subsection{Limitation and future study}

Whilst the use of experimental design which includes a realistic scenario enhances the internal validity, it reduces the external validity. Therefore, the results of this study are not readily generalizable. In other words, caution should be taken to view the results of this study. To improve the generalizability, future study might want to duplicate this study and extend it to other service contexts, such as airlines or banks or using other methods.

\section{CONCLUSION}

This study was undertaken to examine the effect of cultural familiarity and severity of service failure on customer satisfaction. A sequential mixed method approach was adopted to conduct the study. Initially, the results of six focus groups were used to develop the quantitative study. Next, data from 740 Australian respondents were gathered via online survey. Significant results of the main and interaction effects of the severity of service failure and cultural familiarity on customer satisfaction were found in the hypotheses tests using ANOVA. These findings offer a new insight into the literature, particularly into the role of cultural familiarity on customer satisfaction; as well as provide considerable business implications.

\section{REFERENCE}

Bitner, M. J., Booms, B. H., \& Mohr, L. A. 1994. Critical service encounters: The employee's viewpoint. Journal of Marketing, 58(4), 95-105

Bowen, J.T. \& Chen, Shiang-Lih. 2001. The relationship between customer loyalty and customer satisfaction. International Journal of Contemporary Hospitality Management, 13(5), 213-217

Donthu, N. \& Yoo, B. (1998).Cultural Influences on Service Quality Expectations. Journal of Service Research, 1(2), 178-186

Furrer, O., Liu, B., \& Sudharshan, D. 2000. The Relationships between Culture and Service Quality Perceptions: Basis for Cross-Cultural Market Segmentation and Resource Allocation. Journal of Service Research, 2(4), 355-371

Lewis, B. R., \& Spyrakopoulos, S. 2001. Service failures and recovery in retail banking: the customers' perspective. International Journal of Bank Marketing, 19(1), 37-47

Mattila, A.S. 2001. The impact of relationship type on customer loyalty in a context of service failures. Journal of Service Research, 4(2), 91-101
Olivier, R.L. 1980. A cognitive model of the antecedents and consequences of satisfaction decisions. The Journal of Consumer Research, 17(4), 460-469

Patterson P.G., Cowley, E., \& Prasongsukarn, K. 2006. Service failure recovery: The moderating impact of individual-level cultural value orientation on perceptions of justice. International Journal of Research in Marketing, 23, 263-277

Patterson P.G. \& Mattila, A.S. 2008. An examination of the impact of cultural orientation and familiarity in service encounter evaluations. International Journal of Service Industry Management, 19(5), 662-681

Perdue, B. C. \& Summers, J. O. 1986. Checking the success of manipulations in marketing experiments. Journal of Marketing Research, XXIII, 317-326

Rao, A.R. \& Monroe, K.B. 1988. The moderating effect of prior knowledge on cue utilization in product evaluations. Journal of Consumer Research, 15, 253-264

Reisinger, L.W. \& Turner, Y. 1997. Cross-cultural differences in tourism: Indonesian tourist in Australian. Journal of Tourism Management, 18(3), 139-147

Reisinger, L.W. \& Turner, Y. 2001. Shopping satisfaction for domestic tourists. Journal of retailing and Consumer Service, $8,15-27$

Sabharwal,N., Soch,H., Kaur,H. 2010. Are we satisfied with incompetent service? A scale development approach for service recovery. Journal of Service Research, 10(1), 125142

Smith, A.K., Bolton, R.N., \& Wagner, J. 1999. A model of customer satisfaction with service encounters involving failure and recovery. Journal of Marketing Research, 36(3), 356372

Sparks, B.A. \& McColl-Kennedy. 2001. Justice strategy and options for increased customer satisfactions in a servicerecovery setting. Journal of Business Research, 54 (3), 209218

Strauss, B. and P. Mang (1999), “'Culture Shocks' in InterCultural Service Encounters?” Journal of Service Marketing, 13 (3/4), 329-346

Trianasari, Sparks, B.A., \& Butcher, K. 2011. Proc. CAUTHE National Conference '11: Exploring the concept of the zone of tolerance in service failure context. Adelaide, South Australia: CAUTHE

Weaver, D., \& Lawton, L. 2010. Tourism Management. Australia:John Wiley \& Sons Australia,Ltd.

Weiermair, Klaus. 2000. Tourists' perceptions towards and satisfaction with service quality in the cross-cultural service encounter: implications for hospitality and tourism management. Managing Service Quality, 10(6), 397-409

$\mathrm{Wu}, \mathrm{Li}-\mathrm{Wei}$. 2011. Satisfaction, inertia, and customer loyalty in the varying levels of the zone of tolerance and alternative attractiveness. Journal of Service Marketing, 25(5), 310-322 